\title{
Bow hunter's syndrome revisited: 2 new cases and literature review of 124 cases
}

\author{
Gregory F. Jost, MD,1,2 and Andrew T. Dailey, MD² \\ ${ }^{1}$ Spine Surgery, University Hospital Basel, Switzerland; and ${ }^{2}$ Department of Neurosurgery, Clinical Neurosciences Center, \\ University of Utah, Salt Lake City, Utah
}

\begin{abstract}
Rotational occlusion of the vertebral artery (VA), or bow hunter's syndrome, is a rare yet surgically treatable cause of vertebrobasilar insufficiency. The underlying pathology is dynamic stenosis of the VA by osteophytes, fibrous bands, or lateral disc herniation with neck rotation or extension. The authors present 2 previously unreported cases of bow hunter's syndrome and summarize 124 cases identified in a literature review.

Both patients in the new cases were treated by VA decompression and fusion of the subaxial spine. Each had $>50 \%$ occlusion of the left VA at the point of entry into the transverse foramen with a contralateral VA that ended in the posterior inferior cerebellar artery. Analyzing data from 126 cases (the 2 new cases in addition to the previously published 124), the authors report that stenosis was noted within $V_{1}$ in $4 \%$ of cases, in $V_{2}$ in $58 \%$, in $V_{3}$ in $36 \%$, and distal to $C-1$ in $2 \%$. Patients presented in the 5 th to 7 th decade of life and were more often male than female. The stenotic area was decompressed in $85(73 \%)$ of the 116 patients for whom the type of treatment was reported $\left(\mathrm{V}_{1}, 4[80 \%]\right.$ of $5 ; \mathrm{V}_{2}, 52$ [83\%] of 63 ; $\mathrm{V}_{3} / \mathrm{V}_{4}, 29[60 \%]$ of 48). Less commonly, fusion or combined decompression and fusion was used $\left(\mathrm{V}_{2}, 7[11 \%]\right.$ of $63 ; \mathrm{V}_{3} / \mathrm{V}_{4}$, 14 [29\%] of 48). Most patients reported complete resolution of symptoms.

The authors conclude that patients with bow hunter's syndrome classically have an impaired collateral blood flow to the brainstem. This condition carries an excellent prognosis with decompression, fusion, or combined surgery, and individual patient characteristics should guide the choice of therapy.
\end{abstract}

http://thejns.org/doi/abs/10.3171/2015.1.FOCUS14791

KEY WORDS bow hunter's syndrome; cervical spine; decompression; dynamic vertebrobasilar insufficiency; fusion; rotational vertebrobasilar insufficiency; vertebral artery; rotational occlusion

"B ow hunter's syndrome" is the descriptive synonym for rotational vertebrobasilar insufficiency. This condition is elicited by rotation or extension of the neck and caused by dynamic and reversible occlusion of the vertebral artery (VA) and lack of collateral blood supply to the brainstem. The literature on bow hunter's syndrome is limited to case reports and small series. Our review of 124 cases reported in the English literature from 1952 to 2011 along with 2 new cases from our own experience summarizes patient characteristics, symptoms, surgical strategies, and outcomes for patients with this rare syndrome of recurrent vertebrobasilar insufficiency that can be cured with spine surgery.

\section{Case Reports}

Case 1

This 55-year-old man had experienced 2 months of syncopal attacks when he extended his neck and loss of vision when he turned his head to the left or up. MRI showed a left-sided foraminal disc herniation at C6-7 and a left dominant VA (Fig. 1). The right VA terminated in the posterior inferior cerebellar artery (PICA). On dynamic angiography, neck extension led to a $20 \%$ stenosis of the left VA and neck rotation to the left to a stenosis of $50 \%$ (Fig. 2). To decompress the left VA, the left transverse foramen of C-6 was unroofed via an anterior approach, and the left

ABBREVIATIONS CTA = CT angiography; DSA = digital subtraction angiography; MRA = MR angiography; PICA = posterior inferior cerebellar artery; SPECT = singlephoton emission CT; VA = vertebral artery.

SUBMITTED December 1, 2014. ACCEPTED January 15, 2015.

INCLUDE WHEN CITING DOI: 10.3171/2015.1.FOCUS14791.

DISCLOSURE This study was supported by the NREF. The authors have no conflicts of interest or industry affiliations related to the prepared work. 


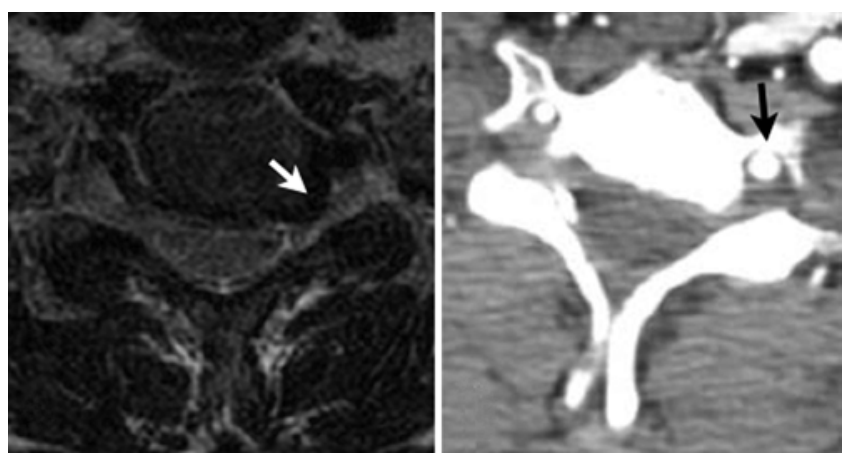

FIG. 1. Case 1. MRI and CTA findings in a 56-year-old patient with bow hunter's syndrome. Left: A foraminal disc herniation is seen at the left C6-7 foramen (white arrow). Right: The left dominant VA (black arrow) has a larger caliber than the right VA.

discoligamentous herniation at $\mathrm{C} 6-7$ and uncarthrosis at C-6 were removed. C- 6 and C-7 were then fused with a tricortical iliac crest allograft and anterior plate. At 6 months' follow-up, the patient could rotate his neck to the left without symptoms and reported minor symptoms with prolonged neck extension.

\section{Case 2}

This 47-year-old woman reported recurrent dizziness, disturbance of vision, and fainting spells triggered by rotating the neck to the left. She had experienced episodic neck and hand pain and upper-extremity clumsiness for several years, consistent with progressive myeloradiculopathy. The results of sensorimotor testing were normal except for brisk reflexes and a Hoffman sign on the right. MRI of the cervical spine revealed spondylosis with a midline disc protrusion at $\mathrm{C} 3-4$, a left foraminal disc herniation at C5-6 (Fig. 3 left), and a broad-based disc herniation at C6-7. Angiography showed dynamic stenosis of the left VA at C5-6, corresponding to the area of the herniated disc (Fig. 3 right). The right VA ended in the PICA. Since the patient had symptomatic cervical spondylosis, the decompression and fusion of C5-6 was extended to the degenerated segments $\mathrm{C} 3-4$ and $\mathrm{C} 6-7$ (not shown). Postoperatively, the fainting spells did not recur, although she continued to experience neck pain and stiffness.

\section{Literature Review}

We searched PubMed for the keywords "bow hunter's syndrome," "bow hunter's stroke," "rotational vertebrobasilar insufficiency," and "dynamic vertebrobasilar insufficiency." All papers written in English were obtained as full articles except for 1 historic report, ${ }^{10}$ and cross references were checked for additional reports, which were also obtained as full articles. An early report on 20 patients with rotational occlusion of the VA proximal to the C-6 transverse foramen and by tendons of the longus colli and scalenus anticus muscle was not included because data were only available in summarized form. ${ }^{17}$

\section{Analysis}

From 1952 to November 2011, 43 papers reported on 124 cases (Tables $1-3$ ). The 2 largest series consisted of 20 cases in the subaxial cervical spine $(\mathrm{C} 3-7)^{28}$ and 17 cases at $\mathrm{C} 1-2 .{ }^{25}$ For purposes of analysis, we are including the 2 cases reported in the present paper, which brings the total number of cases analyzed to 126 .

\section{Patient Characteristics}

Including our patients, there were 2 pediatric patients, ${ }^{6}$ 3 adolescents, ${ }^{6,10,22}$ and 121 adults (Fig. 4). Occlusion was located proximal to C-7 $\left(\mathrm{V}_{1}\right)$ in $5(4 \%)$ cases, between C-3 and $\mathrm{C}-7\left(\mathrm{~V}_{2}\right)$ in $73(58 \%)$, at $\mathrm{Cl}-2\left(\mathrm{~V}_{3}\right)$ in $45(36 \%)$, and distal to $\mathrm{C}-1\left(\mathrm{~V}_{4}\right)$ in $3(2 \%)$. Patients typically presented in the 5th to 7th decade of life; the mean age at presentation was $54 \pm 7$ years for patients with occlusion at $V_{1}, 57 \pm 12$ years for occlusion at $V_{2}$, and $53 \pm 18$ years for occlusion at $\mathrm{V}_{3}$. The mean age at diagnosis in all of the adults was $57 \pm$ 11 years. The male-to-female distribution was 2:1 overall, with $80 \%$ of cases in the $V_{1}$ segment, $74 \%$ in the $V_{2}$, and $61 \%$ in the $\mathrm{V}_{3}$ and $\mathrm{V}_{4}$ segments occurring in male patients.

Dynamic stenosis of the VA was relatively evenly distributed between the left (49.5\%) and right (36.7\%) sides; it was bilateral in $13.7 \%$ of cases. Pediatric patients presented with congenital anomalies such as a bony malformation at $\mathrm{C} 1-2$ or a suboccipital bony protuberance impinging on the VA. ${ }^{6,22}$ In adults, the compressive cause depended on the location. At the craniocervical junction, the VA was fixed to an ossified or thickened atlanto-occipital membrane (Fig. 5) ${ }^{37,41}$ or compressed by a dural fold in the foramen magnum, ${ }^{1}$ an assimilated posterior ring of C-1 with bilateral condylar and clival hypoplasia and platybasia, ${ }^{34}$ an accessory ossicle behind the left atlanto-odontoid junction,,$^{53}$ erosive rheumatoid arthritis of $\mathrm{C} 1-2,{ }^{36}$ or $\mathrm{C} 1-2$ facet hypertrophy. ${ }^{5}$ In the subaxial cervical spine, the VA was most frequently compressed by a bone spur of a hypertrophied uncovertebral joint, $, 13,15,28,32,42,50$ rarely by a laterally herniated disc. ${ }^{30,49}$ In 1 case, the VA was impinged by scissoring between the anterior root of the upper transverse process and a subluxating superior articular process of the inferior vertebral body; ${ }^{19}$ in another case, there was a chronic VA dissection: ${ }^{18}$ and in a third case, an anomalous prevertebral course, with the VA entering the transverse foramen at C-4 only, led to a compression of the VA between the thyroid cartilage and the anterior aspect of the C-6 transverse process.? Fibrous bands and a tight scalenovertebral angle resulted in dynamic flow obstruction in the first segment of the VA. ${ }^{12,21,23,39,45}$ Although most cases manifested spontaneously, a posttraumatic onset of symptoms has also been reported. ${ }^{41,53}$

By definition, rotational vertebrobasilar insufficiency is characterized by reversible symptoms that are elicited upon neck rotation. The most commonly reported symptoms were syncopes, near-syncopes, and drop attacks; vertigo; dizziness; and impaired vision (Table 4). Other symptoms, including paresis, deficits, and pain, were also reported. Symptoms were present before diagnosis for a median of 12 months (range 1 week to 20 years).

Dynamic angiography and later digital subtraction angiography (DSA), CT angiography (CTA) and MR angiography (MRA) with and without 3D reconstructions, extracranial and transcranial Doppler sonography, and single-photon emission CT (SPECT) were all used in the evaluation of patients. Dynamic angiography and Doppler 


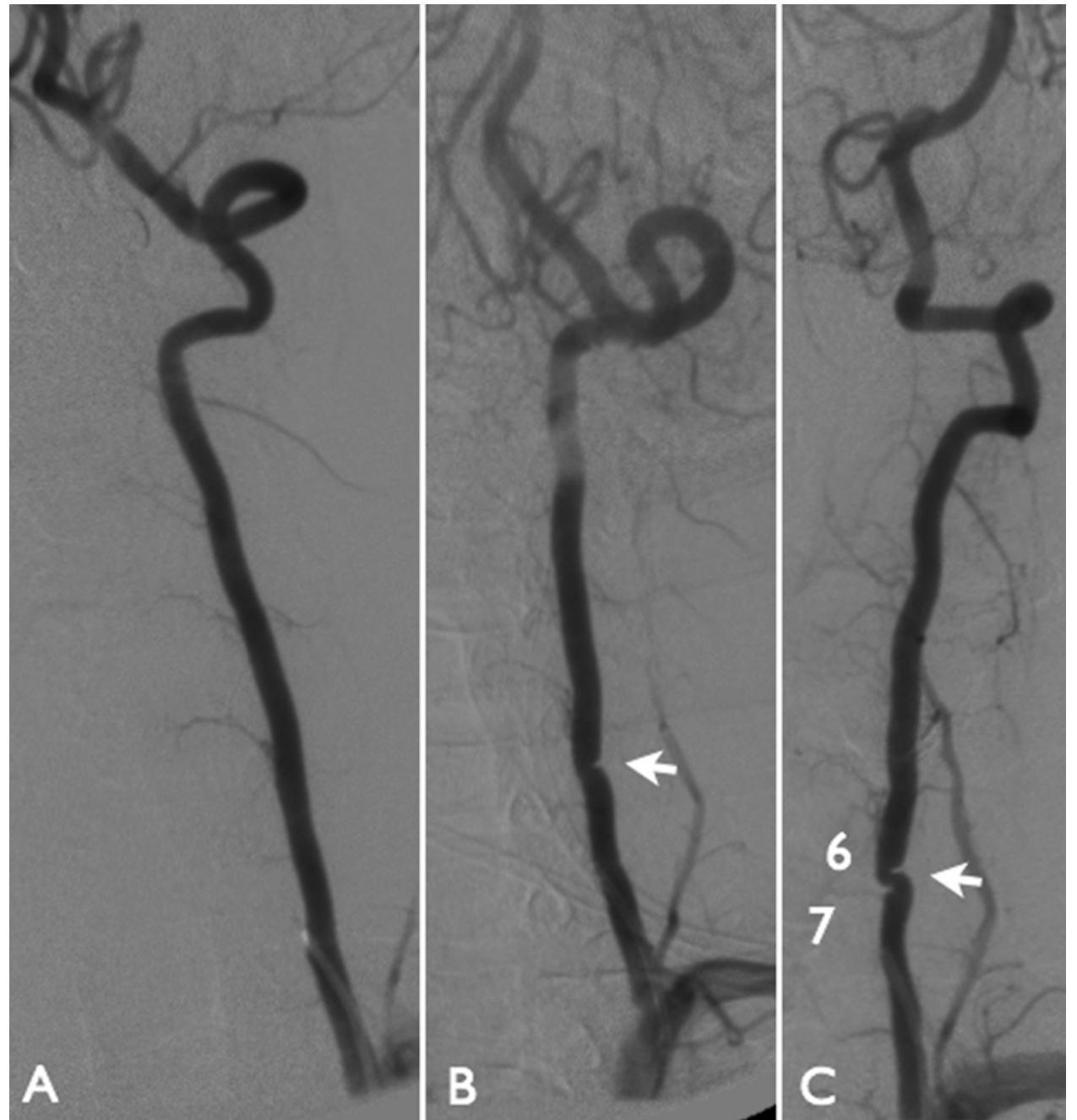

FIG. 2. Case 1. Dynamic angiography of the left VA in a 56-year-old patient with bow hunter's syndrome. A: The left VA is dominant and fully patent in the neutral position. B: Neck extension causes a $20 \%$ stenosis at C6-7. C: Neck rotation to the left causes a $50 \%$ stenosis.

sonography were also applied intra- and postoperatively to document resolution of the stenosis..$^{50,51,53}$

At $\mathrm{C} 1-2$, the stenosis was on the right side in $30 \%$ of the patients for whom the affected side was specified (13 of 44) and on the left in 64\% (28 of 44). Three patients (7\%) had bilateral stenosis, ${ }^{5,6}$ and the affected side was not indicated in 1 case (Fig. 4). ${ }^{10}$ In the 3 patients with stenosis distal to $\mathrm{C}-1$, it was bilateral in 1 , on the left in 1 , and on the right in 1. From C-3 to C-7, the stenosis was on the right side in $40 \%$ of the patients for whom the side was specified (23 of 57), on the left in 40\% (23 of 57), bilateral in 19\% (11 of 57). The stenotic side was not specified in 16 cases. Monosegmental stenosis was observed in 52 patients, multisegmental in 8 including 1 patient with stenosis at C5-6 and C1-2. In 13 patients the stenotic level within $\mathrm{V}_{2}$ was not specified.

Where mentioned, symptoms were exclusively triggered by a contralateral neck rotation in patients with a stenosis of the VA at $\mathrm{C} 1-2$. In contrast, an ipsilateral neck rotation evoked symptoms in $94 \%$ of patients (34 of 36) with a subaxial stenosis of the VA $\left(\mathrm{V}_{2}\right)$. It was also reproducible by a contralateral rotation in $8 \%(3 \text { of } 36)^{3,13,40}$ and exclusively by a contralateral rotation in 1 case.${ }^{51}$ Three of 5 patients with a dynamic stenosis of the VA proximal to C-7 were affected on the right side and 2 on the left. Symptoms were caused by ipsilateral rotation in 3 and contralateral rotation in 2 patients. Threshold angles at which neck rotation triggered symptoms were $30^{\circ}, 4,30$ $45^{\circ}, 5,20,34,37,4955^{\circ}, 960^{\circ},{ }^{45,52}$ and $90^{\circ} .{ }^{19,47}$ In 22 papers, the authors reported that the contralateral VA of their patients was hypoplastic, absent, or terminating in a PICA, and 6 noted a deficient circle of Willis with absent posterior communicating arteries (Tables 1-3).

\section{Conservative Management}

Management strategies were described for 116 of the cases (Table 5). In total, 9 cases (8\%) were initially managed conservatively, including 4 cases in which patients chose conservative therapy (cervical collar, refraining from extreme neck rotations, aspirin) despite recommended surgery. ${ }^{16,34,36,37}$ One patient chose conservative therapy because symptoms were only triggered by extreme neck rotation during chiropractic maneuvers.? In another pa- 


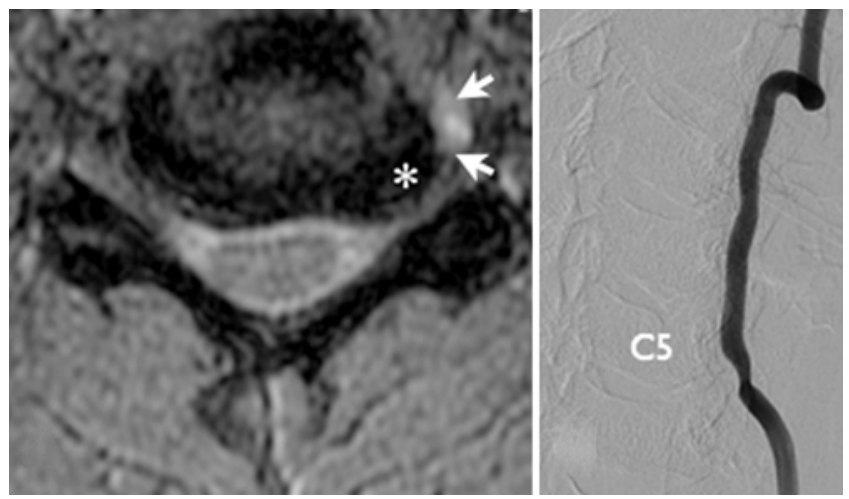

FIG. 3. Case 2. MRI and angiographic findings in a 47-year-old patient with bow hunter's syndrome. Left: MR image shows a left foraminal disc herniation (asterisk) that abuts the left VA (arrows). Right: Angiogram revealing the corresponding stenosis of the left VA at C5-6.

tient, bow hunter's syndrome was brought on by a dissected contralateral VA. Symptoms disappeared with recanalization of the dissection. ${ }^{52}$ One patient was treated with halter traction. ${ }^{40}$ Two patients were initially treated with a trial of bracing and subsequently underwent decompression surgery. ${ }^{11,13}$

\section{Interventional Management and Bypass Surgery}

Two patients had stents placed: ${ }^{29,45}$ In 1 patient with a VA stenosis in the subaxial cervical spine and a concomitant ostial atherosclerotic stenosis of the same artery, symptoms disappeared after stenting of the ostial atherosclerotic stenosis, which increased perfusion pressure across the subaxial stenosis. ${ }^{29}$ One patient underwent a PICA to PICA bypass surgery. ${ }^{18}$

\section{Decompression}

The stenotic area was treated with decompression in $85(73 \%)$ of the 116 patients for whom management strategies were described $\left(\mathrm{V}_{1}, 4\right.$ [80\%] of $5 ; \mathrm{V}_{2}, 52$ [83\%] of 63; $\mathrm{V}_{3}$ and $\mathrm{V}_{4}, 29$ [60\%] of 48), and symptoms improved or disappeared in $87 \%$ of the patients with available followup (65 of 75) (Table 6). Six patients (8\%) experienced residual or persistent symptoms: vertigo, ${ }^{6}$ hemiparesis, ${ }^{6}$ dizziness, ${ }^{51}$ and persistent syncopes ${ }^{51}$ Symptoms improved after secondary fusion of $\mathrm{C} 1-2$ in 1 patient. Symptoms recurred in 4 patients; ${ }^{19,25} 2$ of these patients underwent a secondary fusion, 1 was treated with anticoagulants, ${ }^{25}$ and 1 patient was only freed of symptoms after 2 decompressions at the same level and an additional decompression at another level..$^{19}$ One patient underwent a secondary fusion procedure because of C1-2 instability. ${ }^{22}$ To decompress a narrowed VA in the subaxial cervical spine, most authors unroofed the transverse foramen by removing the costal process and, if present, any impinging discoligamentous tissue. ${ }^{22}$ Resecting the fibrous adventitia around the VA was also recommended. ${ }^{51}$ Stenoses at the craniocervical junction were approached from posterior ${ }^{14,41}$ or anterolateral $^{6,11}$ directions.

\section{Fusion}

Thirteen (27\%) of 48 patients with stenosis at $\mathrm{C} 1-2$ or 


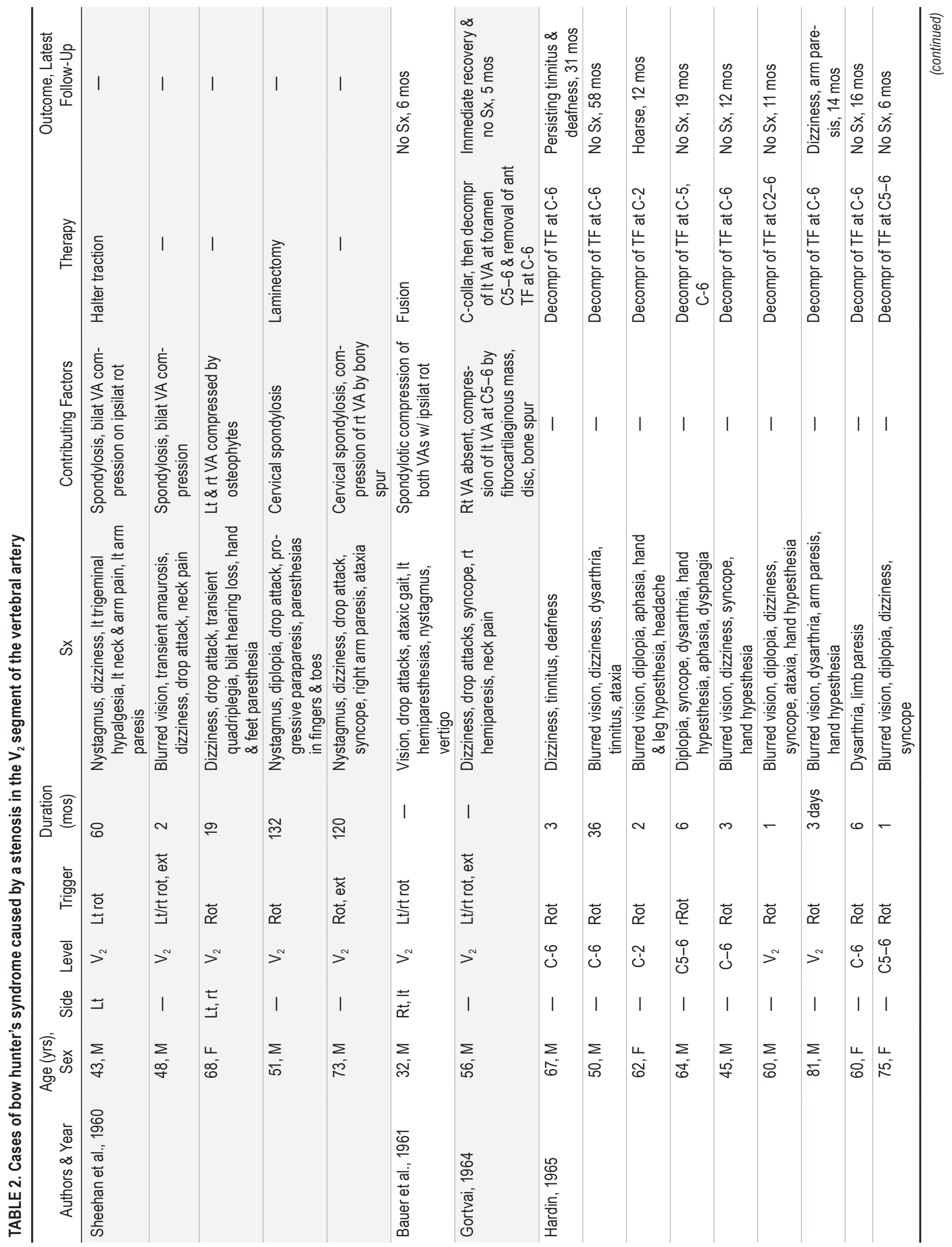




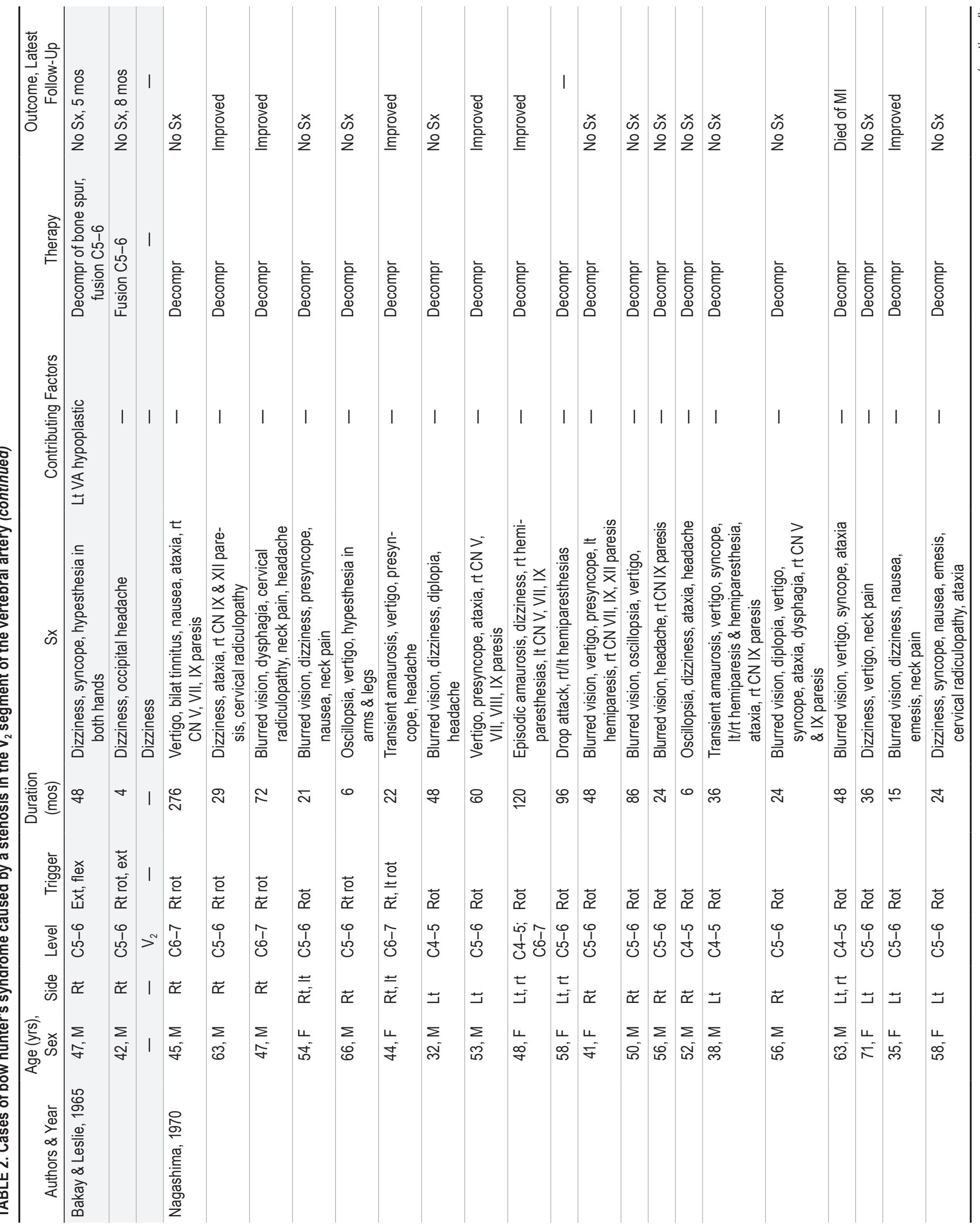




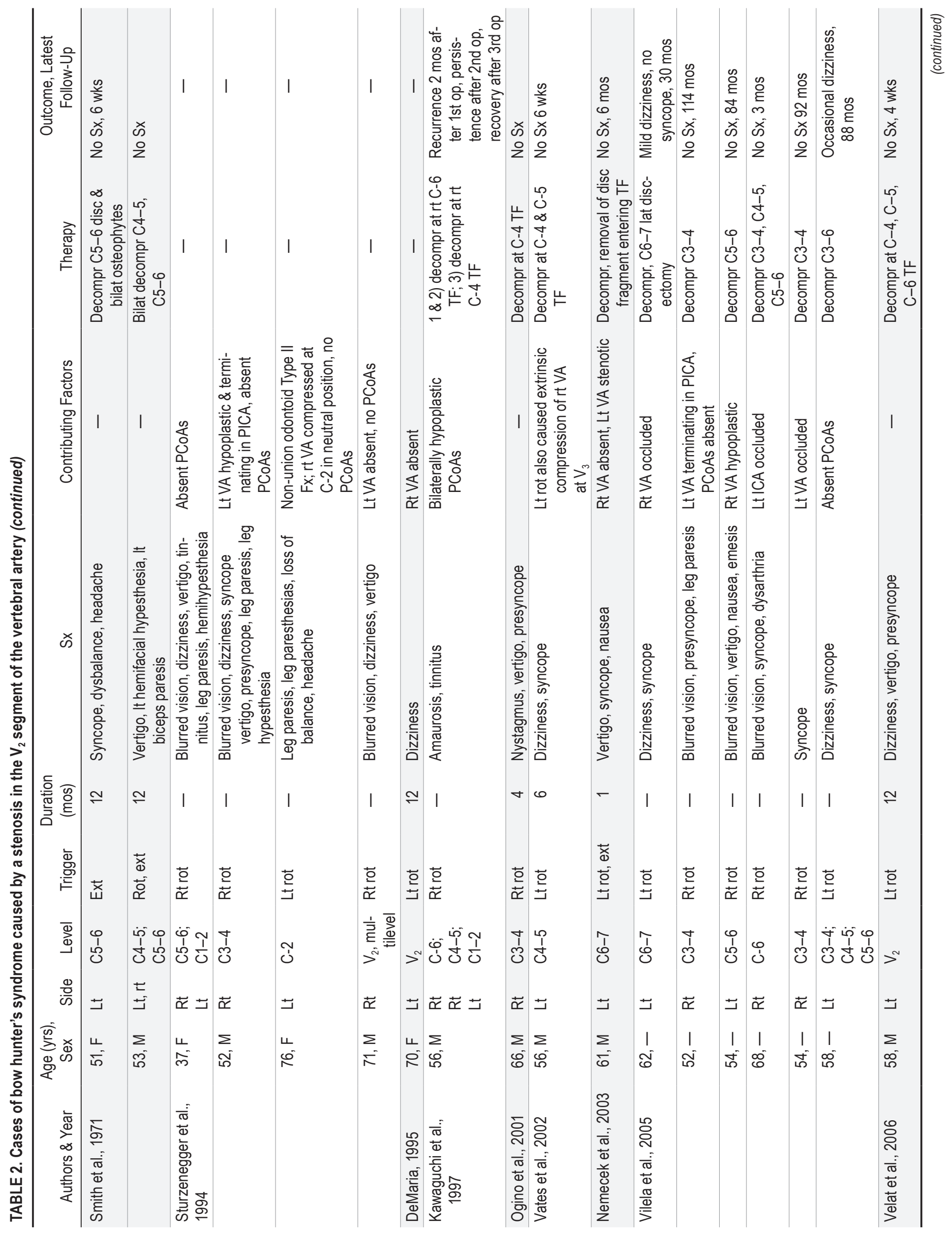




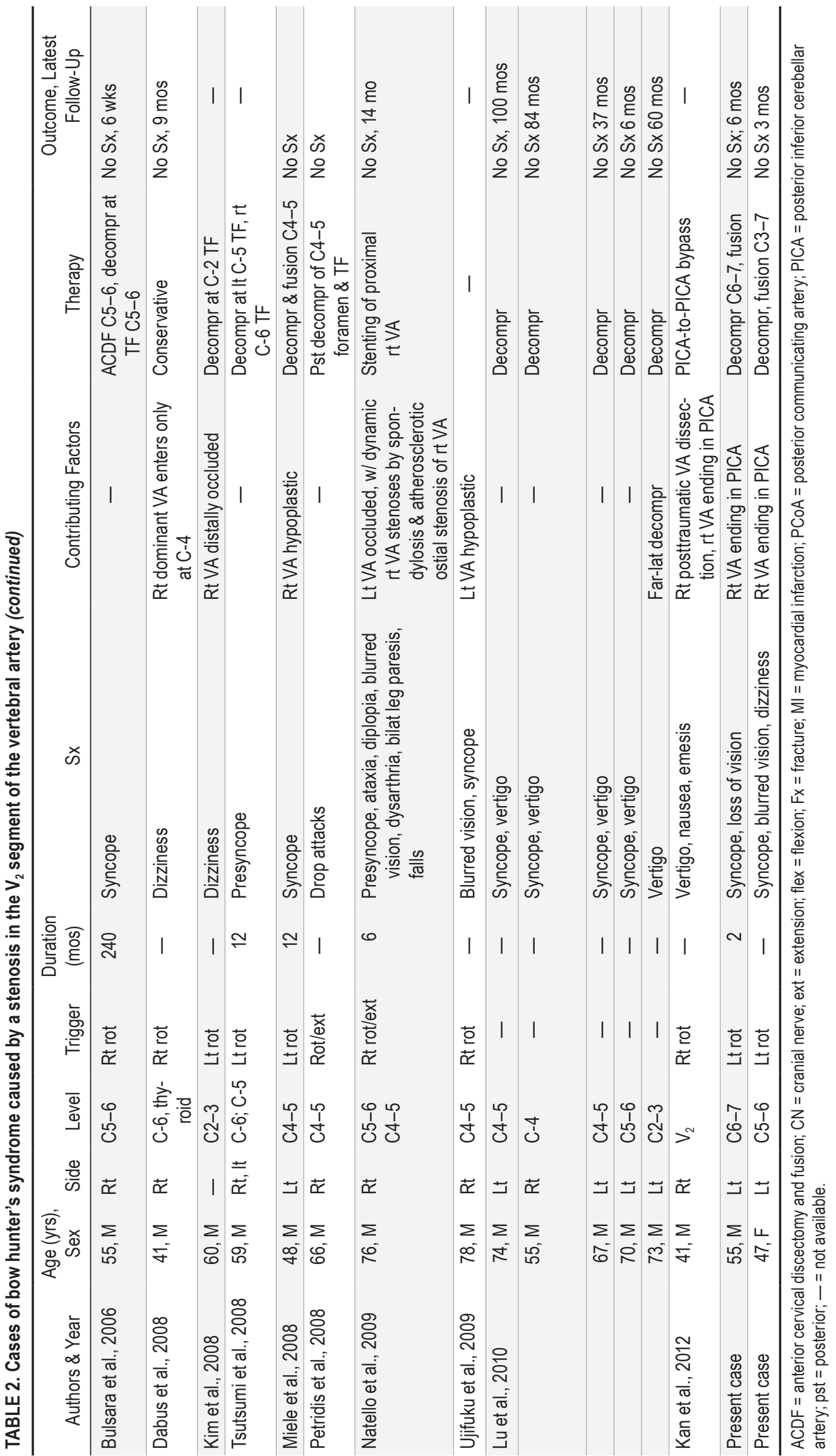




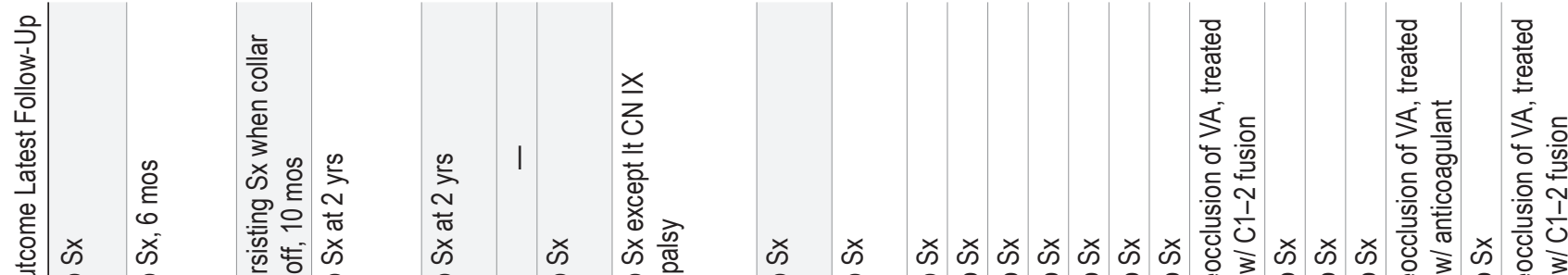

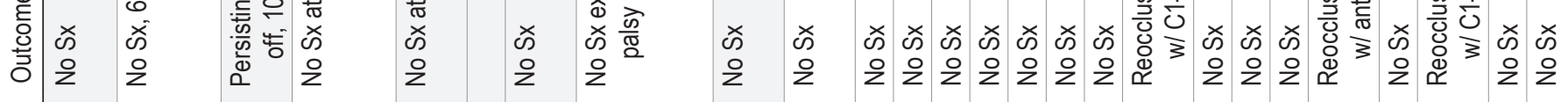
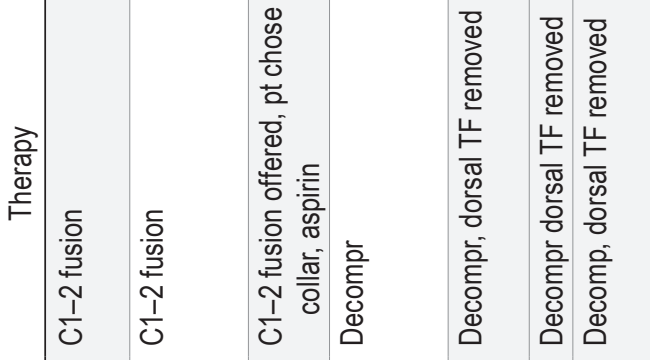

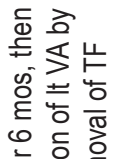

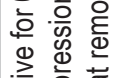

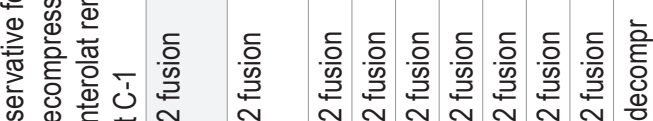
离尊

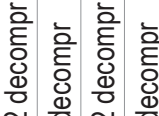
享 㐔

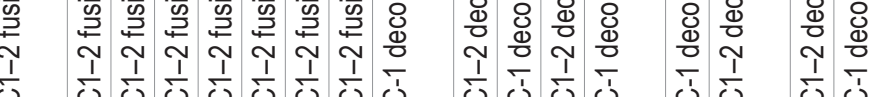

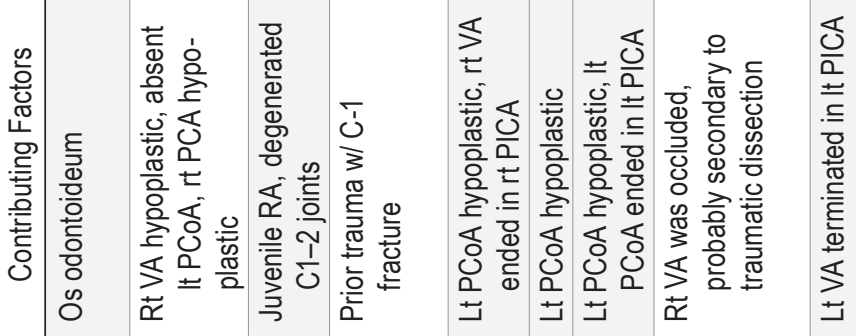

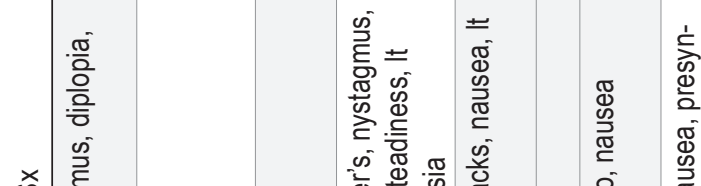

œ

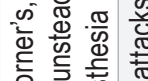
훌에 은 蛋

$>$

$\stackrel{\oplus}{ \pm}$

을

政

일

혼

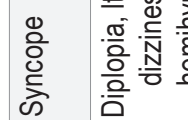

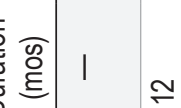

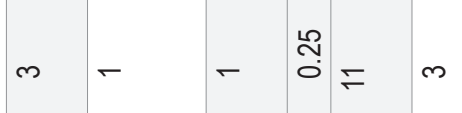

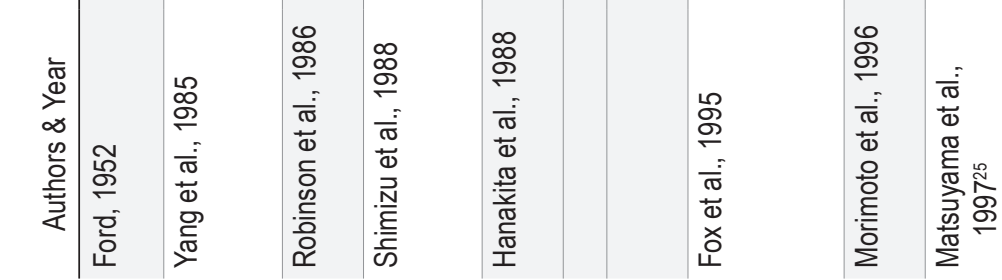
o. $\frac{0}{50}$

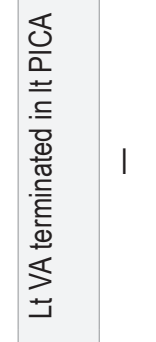

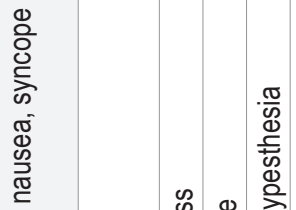

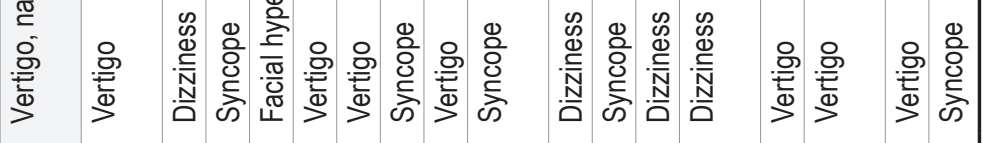

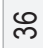

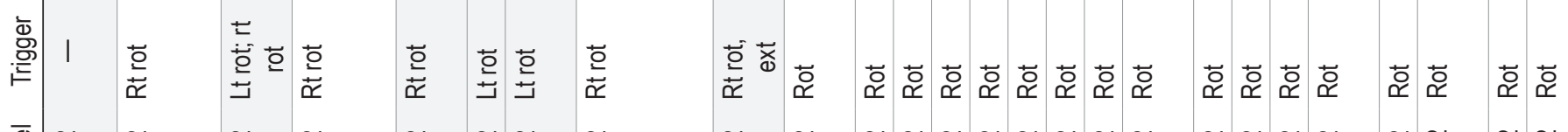

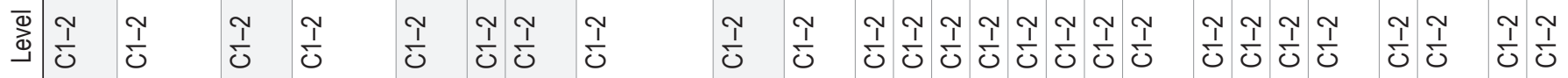

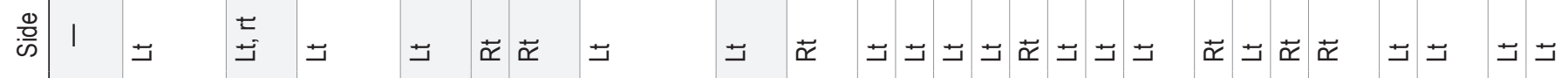

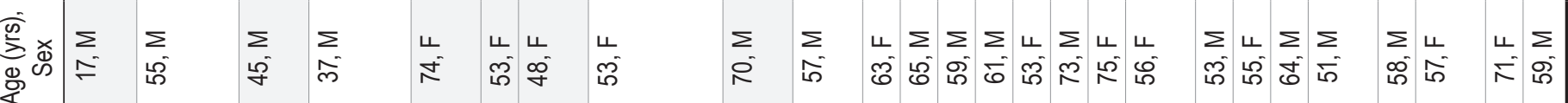




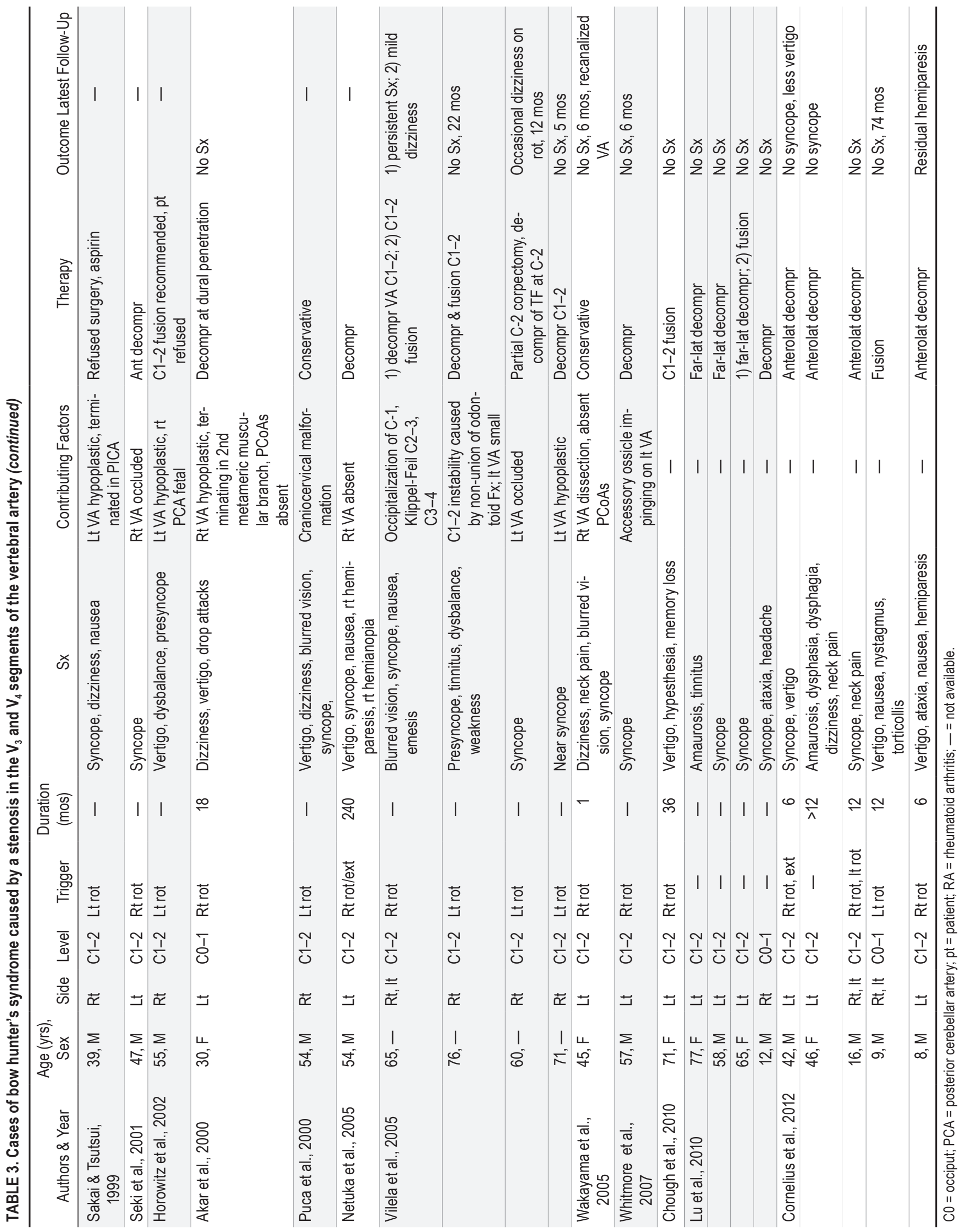




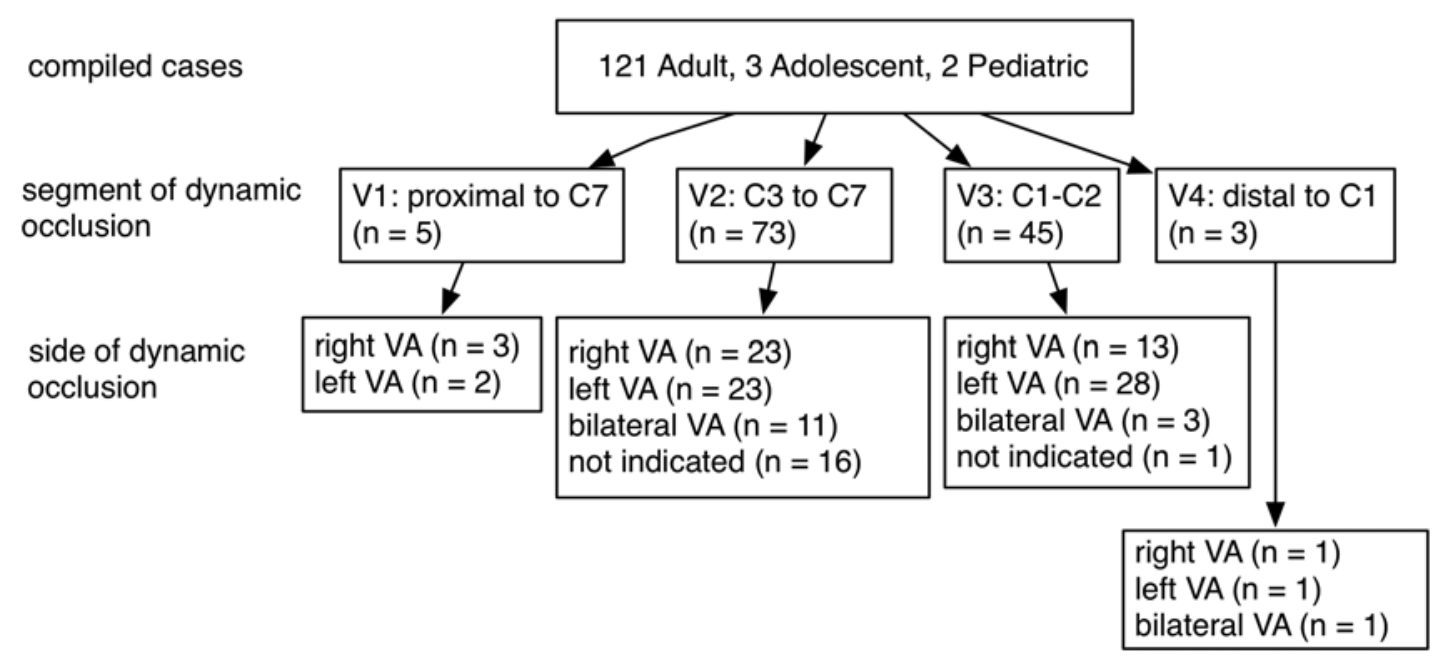

FIG. 4. Location of dynamic occlusion of the VA. Among patients categorized as having $V_{2}$ occlusions, 8 were described as having multisegmental occlusions. In 52 cases, the occlusions were specifically described as monosegmental, while in the remaining 13 , information about the number of segments affected was not provided.

distal to C-1 underwent atlantoaxial or occipitocervical fusion,,$^{10,24,27,54}$ and $2(3 \%)$ of 63 patients with compression at $\mathrm{V}_{2}$ had fusion in the subaxial cervical spine $\mathrm{e}^{2,3}$ without exposure and decompression of the VA. All were reported to have symptom-free outcomes.

\section{Decompression and Fusion}

Five $(8 \%)$ of 63 patients with compression at $\mathrm{V}_{2}$, including our 2 patients, had decompression and fusion during the same surgery for a stenosis of the VA in the subaxial cervical spine, ${ }^{2,4}$ and 1 patient with a stenosis involving C1-2 was treated with decompression and occipitocervical fusion. ${ }^{51}$ No recurrences were noted.

\section{Discussion}

Sorensen ${ }^{43}$ coined the term "bow hunter's syndrome" after a patient who developed Wallenberg stroke during archery practice. This is in the strict sense different from the reversible symptoms of rotational vertebrobasilar insufficiency that are usually described as bow hunter's syndrome. Therefore, we have not included Sorensen's case, which remains the only report of the syndrome in a bow hunter. Although a 3-tiered classification has been proposed to distinguish different causes,${ }^{37}$ most authors have adopted the term to refer to rotational vertebrobasilar insufficiency.

The summarized data enable us to characterize this rare syndrome: typically, a patient presents in the 6th decade, is male, and experiences reversible symptoms of vertebrobasilar insufficiency upon neck rotation. Symptoms are most likely syncopal or near-syncopal events, drop attacks, vertigo and dizziness, and impaired vision. Imag-
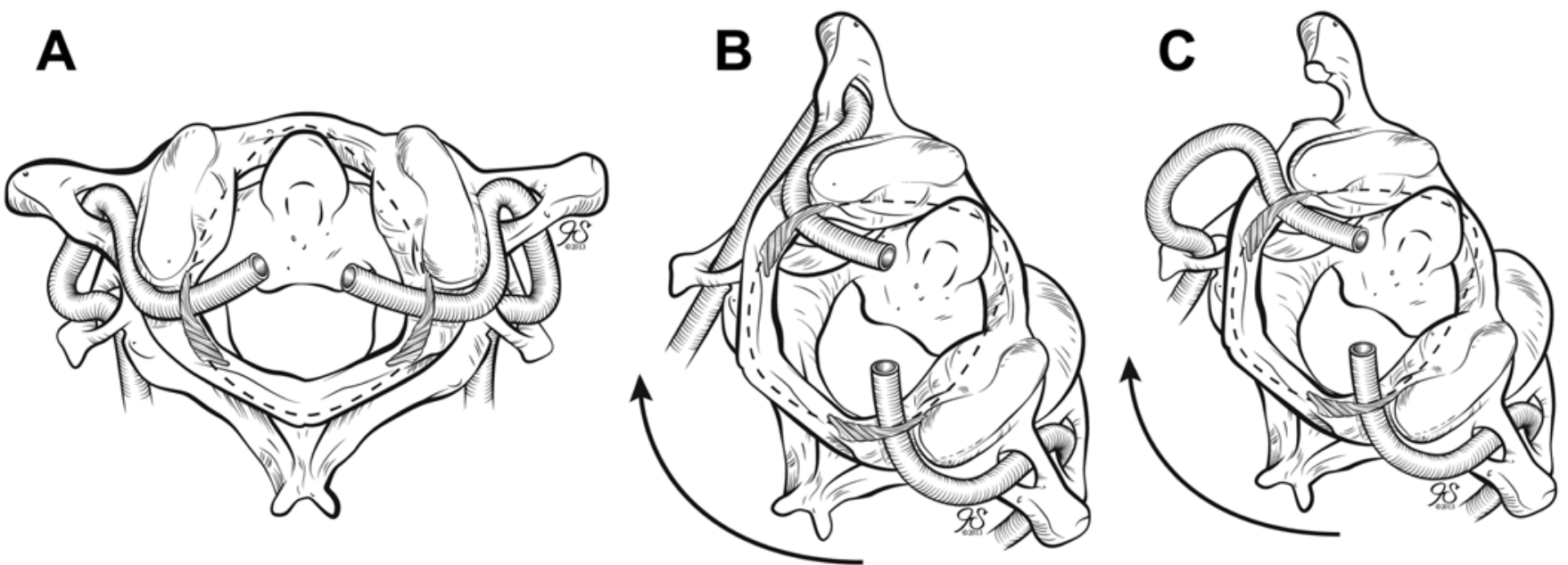

FIG. 5. Illustrations showing a potential cause of bow hunter's syndrome involving the $V_{3}$ segment of the vertebral artery. Although a patient may experience no symptoms when the cervical vertebrae are in a neutral position (A), contralateral rotation (B) may elongate and squeeze the VA under a thickened atlanto-occipital membrane in the vascular groove and transverse foramen of the atlas. Resection of the atlanto-occipital membrane and opening the transverse foramen (C) frees the artery and eliminates the compression. Copyright Department of Neurosurgery, University of Utah. Published with permisison. 
TABLE 4. Symptoms reported in 126 patients with bow hunter's syndrome

\begin{tabular}{lc}
\hline \multicolumn{1}{c}{ Symptom } & No. of Patients $(\%)$ \\
\hline Syncope, near syncope, drop attacks & $69(54)$ \\
\hline Vertigo & $49(39)$ \\
\hline Dizziness & $45(35)$ \\
\hline Impaired vision & $43(34)$ \\
\hline Limb paresis & $21(17)$ \\
\hline Ataxia & $20(16)$ \\
\hline Nausea, emesis & $19(15)$ \\
\hline Cranial nerve deficits & $16(13)$ \\
\hline Hypesthesia & $12(9)$ \\
\hline Diplopia & $10(8)$ \\
\hline Paresthesia & $9(7)$ \\
\hline Headache & $9(7)$ \\
\hline Neck pain & $7(6)$ \\
\hline Tinnitus & $7(6)$ \\
\hline Nystagmus & $7(6)$ \\
\hline Dysarthria, aphasia & $7(6)$ \\
\hline Arm pain & $5(4)$ \\
\hline Dysphagia & $4(3)$ \\
\hline Hypoacusis & $2(2)$ \\
\hline
\end{tabular}

ing is likely to reveal dynamic stenosis of the VA in the subaxial cervical spine in two-thirds of patients and at the craniocervical junction in one-third. This may be associated with a poor collateralization: either a hypoplastic or an absent contralateral VA or a deficient circle of Willis. Symptoms are most commonly elicited by ipsilateral rotation if the occlusion is in the subaxial cervical spine and by contralateral rotation if the occlusion is at the craniocervical junction. The condition is usually caused by degenerative changes in adults and congenital anomalies of the craniocervical junction in pediatric patients. Surgical therapy carries an excellent prognosis.

Conservative therapy is limited to wearing a cervical collar and receiving verbal warnings to avoid extreme neck rotations or to antiplatelet therapy intended to im-

TABLE 5. Treatment stratified by segment

\begin{tabular}{lcccc}
\hline \multicolumn{1}{c}{ Treatment } & \multicolumn{1}{c}{$\mathrm{V}_{1}$} & $\mathrm{~V}_{2}$ & $\mathrm{~V}_{3}$ & $\mathrm{~V}_{4}$ \\
\hline Not reported & \multicolumn{5}{c}{$10 / 73(14 \%)$} \\
\hline Conservative* $^{*}$ & $2 / 63(3 \%)$ & $5 / 45(11 \%)$ \\
\hline Decompr & $4 / 5(80 \%)$ & $52 / 63(83 \%)$ & $27 / 45(60 \%)$ & $2 / 3(67 \%)$ \\
\hline Fusion & $0 / 5$ & $2 / 63(3 \%)$ & $12 / 45(27 \%)$ & $1 / 3(33 \%)$ \\
\hline Decompr \& fusion & $0 / 5$ & $5 / 63(8 \%)$ & $1 / 45(2 \%)$ & \\
\hline $\begin{array}{l}\text { Secondary fusiont } \\
\text { VA stent }\end{array}$ & $1 / 5(20 \%)$ & $1 / 63(2 \%)$ & $4 / 27(15 \%)$ & \\
\hline $\begin{array}{l}\text { PICA-to-PICA } \\
\text { bypass }\end{array}$ & $1 / 63(2 \%)$ & \\
\hline
\end{tabular}

* Count does not include patients who underwent a surgery after failed conservative treatment.

$\dagger$ Of the 27 patients who underwent VA decompression, 4 underwent a secondary fusion procedure because of persistent or recurrent symptoms.
TABLE 6. Outcome of decompression and/or fusion*

\begin{tabular}{lccc}
\hline \multicolumn{1}{c}{ Treatment } & Asymptomatic & $\begin{array}{c}\text { Sx } \\
\text { Persistence }\end{array}$ & $\begin{array}{c}\text { Sx } \\
\text { Recurrence }\end{array}$ \\
\hline Decompr & $65 / 75(87 \%)$ & $6 / 75(8 \%)$ & $4 / 75(5 \%)$ \\
\hline Fusion & $14 / 14(100 \%)$ & 0 & 0 \\
\hline Decompr \& fusion & $6 / 6(100 \%)$ & 0 & 0 \\
\hline
\end{tabular}

* Based on reports with available outcome data.

prove perfusion across the stenosis. In a minority of the reviewed cases, the patients did not have surgery, and follow-up was only reported in 3 of these cases: one patient did fine with a cervical collar and aspirin but experienced recurrent symptoms whenever the collar was off; ${ }^{36}$ in the 2 other cases, the patients were referred for surgical treatment after failure of bracing. ${ }^{11,13}$ We therefore conclude that conservative therapy plays a marginal role and may not suit the lifestyle of the typical patient.

The options for surgery include decompression, fusion, or a combination. The literature suggests an excellent outcome regardless of the strategy. Most authors performed decompression without fusion, and this resolved the symptoms in $87 \%$ of patients. None of the patients who had fusion or decompression and fusion had recurrence of symptoms. Fusion was also a successful salvage procedure for recurrences or persistent symptoms after decompression. ${ }^{19,51}$ Thus, anecdotal evidence suggests that fewer recurrences of bow hunter's syndrome occur with fusion than with decompression alone. This must be weighed, however, against the drawbacks of fusion procedures, particularly at the occipitocervical junction, where neck rotation will be noticeably reduced. Lastly, the comfort level of the surgeon is likely to influence the choice of treatment: an anterior fusion procedure in the subaxial cervical spine or a posterior fusion at the occipitocervical junction may appear more straightforward to the spine surgeon who has limited experience with decompression of the VA.

\section{Workup and Management Algorithm}

In Fig. 6, we suggest a treatment and management algorithm. Given the natural history of rotational vertebrobasilar insufficiency, transcranial Doppler confirms the diagnosis if velocities of the posterior cerebral arteries drop by $\geq 50 \%$ upon neck rotation and surpass baseline values by $\geq 10 \%$ when the patient resumes a neutral neck posture. ${ }^{44,51}$ Hemodynamic compromise with head rotation can also be evaluated with SPECT. ${ }^{24}$ Dynamic imaging studies such as DSA, CTA, or MRA reveal the side and localization of the reversible stenosis and the status of the contralateral VA and circle of Willis. ${ }^{16}$ A decompression without fusion may be appropriate if degenerative changes are limited. Conversely, anecdotal evidence suggests that a fusion procedure decreases the likelihood of postoperative recurrence, particularly at $\mathrm{C} 1-2$, but limits neck rotation by $50 \%-70 \% .{ }^{24}$ Intraoperative or postoperative Doppler ultrasound, ${ }^{51,53}$ dynamic DSA, ${ }^{50}$ CTA, or MRA can be used to monitor successful decompression of the VA. Recurrent symptoms in a patient who has not had a fusion procedure are best managed by fusion of the causative segments. ${ }^{24}$ 


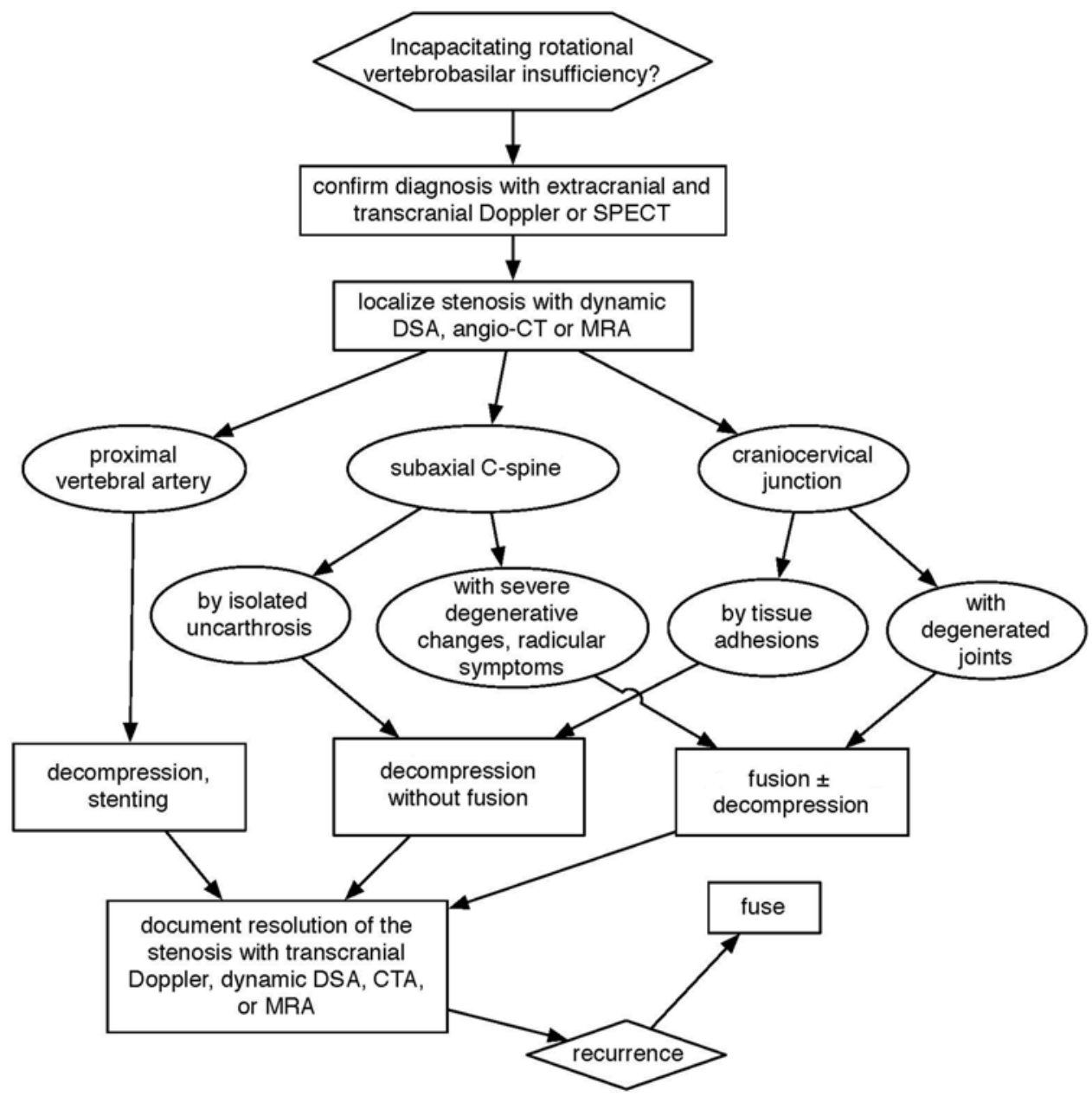

FIG. 6. Diagram showing proposed management algorithm for rotational vertebrobasilar insufficiency.

\section{Impaired Collateralization at Baseline and Physiological Versus Pathological Dynamic Stenosis}

Impaired collateral blood supply to the posterior circulation is common: Hypoplasia of one VA occurs in $10 \%$ to $20 \%$ of patients, ${ }^{44}$ and termination of the VA in the PICA is the second most frequent anomaly. Moreover, the circle of Willis often reveals impaired collateralization, as hypoplasia involving the posterior communicating arteries was present in $68 \%$ of specimens obtained from adults presenting with neurological dysfunction. ${ }^{35}$ These configurations may predispose a patient to vertebrobasilar insufficiency during dynamic occlusion of the VA, which can be physiological or pathological:3,8,40,46 Stretching of the contralateral VA in its $\mathrm{C} 1-2$ course as well as forward and lateral pressure by the lateral mass of $\mathrm{C}-1$ causes physiological rotational stenosis. Conversely, spondylotic changes in the vicinity of the course of the artery through the transverse foramen can impinge on the VA and decrease flow during ipsilateral head rotation. ${ }^{40}$

\section{Limitations}

Our data were retrieved from case reports and clinical series, all of which were retrospective and differed in the extent of available information for each case. For instance, some authors probably confined symptoms to the most rel- evant ones, omitting others, or did not report the detailed findings of cerebral arteriography. Moreover, other important data, such as long-term follow-up, were often missing. Still, this compilation of 126 cases represents the largest overview of bow hunter's syndrome to date, and the descriptive analysis of the retrieved data allowed us to create a characteristic patient scenario and develop a treatment and management algorithm for workup and therapy.

\section{Conclusions}

Bow hunter's syndrome, or rotational vertebrobasilar insufficiency, most often involves syncopal or presyncopal attacks, vertigo, and/or impaired vision, although the symptoms may vary. It usually develops in the 6th decade. It is caused by dynamic and reversible occlusion of the VA with neck rotation, more frequently in the subaxial spine than at the occipitocervical junction. Patients classically have an impaired collateral blood flow to the brainstem. This condition carries an excellent prognosis with decompression, fusion, or a combined surgery.

\section{Acknowledgment}

We wish to thank Kristin Kraus, MSc, for assistance in editing this manuscript. 


\section{References}

1. Akar Z, Kafadar AM, Tanriover N, Dashti RS, Islak C, Kocer $\mathrm{N}$, et al: Rotational compression of the vertebral artery at the point of dural penetration. Case report. J Neurosurg 93 (2 Suppl):300-303, 2000

2. Bakay L, Leslie EV: Surgical treatment of vertebral artery insufficiency caused by cervical spondylosis. J Neurosurg 23:596-602, 1965

3. Bauer R, Sheehan S, Meyer JS: Arteriographic study of cerebrovascular disease. II. Cerebral symptoms due to kinking, tortuosity, and compression of carotid and vertebral arteries in the neck. Arch Neurol 4:119-131, 1961

4. Bulsara KR, Velez DA, Villavicencio A: Rotational vertebral artery insufficiency resulting from cervical spondylosis: case report and review of the literature. Surg Neurol 65:625-627, 2006

5. Chough CK, Cheng BC, Welch WC, Park CK: Bow hunter's stroke caused by a severe facet hypertrophy of C1-2. J Korean Neurosurg Soc 47:134-136, 2010

6. Cornelius JF, George B, N'dri Oka D, Spiriev T, Steiger HJ, Hänggi D: Bow-hunter's syndrome caused by dynamic vertebral artery stenosis at the cranio-cervical junction-a management algorithm based on a systematic review and a clinical series. Neurosurg Rev 35:127-135, 2012

7. Dabus G, Gerstle RJ, Parsons M, Cross DT III, Moran CJ, Thompson R, et al: Rotational vertebrobasilar insufficiency due to dynamic compression of the dominant vertebral artery by the thyroid cartilage and occlusion of the contralateral vertebral artery at C1-2 level. J Neuroimaging 18:184-187, 2008

8. De Kleyn A, Nieuwenhuyse AC: Schwindelanfälle und Nystagmus bei einer bestimmten Stellung des Kopfes. Acta Otolaryngol 11:155-157, 1927

9. DeMaria AA Jr: Positional compression of vertebral artery shown by magnetic resonance angiography. South Med J 88:871-872, 1995

10. Ford FR: Syncope, vertigo and disturbances of vision resulting from intermittent obstruction of the vertebral arteries due to defect in the odontoid process and excessive mobility of the second cervical vertebra. Bull Johns Hopkins Hosp 91:168-173, 1952

11. Fox MW, Piepgras DG, Bartleson JD: Anterolateral decompression of the atlantoaxial vertebral artery for symptomatic positional occlusion of the vertebral artery. Case report. J Neurosurg 83:737-740, 1995

12. Fujimoto S, Terai Y, Itoh T: Rotational stenosis of the first segment of the vertebral artery through compression by the cervical sympathetic chain-case report. Neurol Med Chir (Tokyo) 28:1020-1023, 1988

13. Gortvai P: Insufficiency of vertebral artery treated by decompression of its cervical part. Br Med J 2:233-234, 1964

14. Hanakita J, Miyake H, Nagayasu S, Nishi S, Suzuki T: Angiographic examination and surgical treatment of bow hunter's stroke. Neurosurgery 23:228-232, 1988

15. Hardin CA: Vertebral artery insufficiency produced by cervical osteoarthritic spurs. Arch Surg 90:629-633, 1965

16. Horowitz M, Jovin T, Balzar J, Welch W, Kassam A: Bow hunter's syndrome in the setting of contralateral vertebral artery stenosis: evaluation and treatment options. Spine (Phila Pa 1976) 27:E495-E498, 2002

17. Husni EA, Bell HS, Storer J: Mechanical occlusion of the vertebral artery. A new clinical concept. JAMA 196:475478, 1966

18. Kan P, Yashar P, Langer DJ, Siddiqui AH, Levy EI: Posterior inferior cerebellar artery to posterior inferior cerebellar artery in situ bypass for the treatment of Bow Hunter's-type dynamic ischemia in holovertebral dissection. World Neurosurg 78:553.e15-553.e17, 2012

19. Kawaguchi T, Fujita S, Hosoda K, Shibata Y, Iwakura M, Ta- maki N: Rotational occlusion of the vertebral artery caused by transverse process hyperrotation and unilateral apophyseal joint subluxation. Case report. J Neurosurg 86:1031-1035, 1997

20. Kim CW, Lee YP, Taylor W, Oygar A, Kim WK: Use of navigation-assisted fluoroscopy to decrease radiation exposure during minimally invasive spine surgery. Spine J 8:584-590, 2008

21. Kojima N, Tamaki N, Fujita K, Matsumoto S: Vertebral artery occlusion at the narrowed "scalenovertebral angle": mechanical vertebral occlusion in the distal first portion. Neurosurgery 16:672-674, 1985

22. Lu DC, Zador Z, Mummaneni PV, Lawton MT: Rotational vertebral artery occlusion-series of 9 cases. Neurosurgery 67:1066-1072, 2010

23. Mapstone T, Spetzler RF: Vertebrobasilar insufficiency secondary to vertebral artery occlusion from a fibrous band. Case report. J Neurosurg 56:581-583, 1982

24. Matsuyama T, Morimoto T, Sakaki T: Bow Hunter's stroke caused by a nondominant vertebral artery occlusion: case report. Neurosurgery 41:1393-1395, 1997

25. Matsuyama T, Morimoto T, Sakaki T: Comparison of C1-2 posterior fusion and decompression of the vertebral artery in the treatment of bow hunter's stroke. J Neurosurg 86:619_ 623,1997

26. Miele VJ, France JC, Rosen CL: Subaxial positional vertebral artery occlusion corrected by decompression and fusion. Spine (Phila Pa 1976) 33:E366-E370, 2008

27. Morimoto T, Kaido T, Uchiyama Y, Tokunaga H, Sakaki T, Iwasaki S: Rotational obstruction of nondominant vertebral artery and ischemia. Case report. J Neurosurg 85:507-509, 1996

28. Nagashima C: Surgical treatment of vertebral artery insufficiency caused by cervical spondylosis. J Neurosurg 32:512521,1970

29. Natello GW, Carroll CM, Katwal AB: Rotational vertebrobasilar ischemia due to vertebral artery dynamic stenoses complicated by an ostial atherosclerotic stenosis. Vasc Med 14:265-269, 2009

30. Nemecek AN, Newell DW, Goodkin R: Transient rotational compression of the vertebral artery caused by herniated cervical disc. Case report. J Neurosurg 98 (1 Suppl):80-83, 2003

31. Netuka D, Benes V, Mikulík R, Kuba R: Symptomatic rotational occlusion of the vertebral artery-case report and review of the literature. Zentralbl Neurochir 66:217-222, 2005

32. Ogino M, Kawamoto T, Asakuno K, Maeda Y, Kim P: Proper management of the rotational vertebral artery occlusion secondary to spondylosis. Clin Neurol Neurosurg 103:250253, 2001

33. Petridis AK, Barth H, Buhl R, Mehdorn HM: Vertebral artery decompression in a patient with rotational occlusion. Acta Neurochir (Wien) 150:391-394, 2008

34. Puca A, Scogna A, Rollo M: Craniovertebral junction malformation and rotational occlusion of the vertebral artery. $\mathbf{B r}$ J Neurosurg 14:361-364, 2000

35. Riggs HE, Rupp C: Variation in form of circle of Willis. The relation of the variations to collateral circulation: anatomic analysis. Arch Neurol 8:8-14, 1963

36. Robinson BP, Seeger JF, Zak SM: Rheumatoid arthritis and positional vertebrobasilar insufficiency. Case report. J Neurosurg 65:111-114, 1986

37. Sakai K, Tsutsui T: Bow hunter's stroke associated with atlantooccipital assimilation-case report. Neurol Med Chir (Tokyo) 39:696-700, 1999

38. Seki T, Hida K, Akino M, Iwasaki Y: Anterior decompression of the atlantoaxial vertebral artery to treat bow hunter's stroke: technical case report. Neurosurgery 49:1474-1476, 2001 
39. Sell JJ, Rael JR, Orrison WW: Rotational vertebrobasilar insufficiency as a component of thoracic outlet syndrome resulting in transient blindness. Case report. J Neurosurg 81:617-619, 1994

40. Sheehan S, Bauer RB, Meyer JS: Vertebral artery compression in cervical spondylosis: arteriographic demonstration during life of vertebral artery insufficiency due to rotation and extension of the neck. Neurology 10:968, 1960

41. Shimizu T, Waga S, Kojima T, Niwa S: Decompression of the vertebral artery for bow-hunter's stroke. Case report. J Neurosurg 69:127-131, 1988

42. Smith DR, Vanderark GD, Kempe LG: Cervical spondylosis causing vertebrobasilar insufficiency: a surgical treatment. J Neurol Neurosurg Psychiatry 34:388-392, 1971

43. Sorensen BF: Bow hunter's stroke. Neurosurgery 2:259-261, 1978

44. Sturzenegger M, Newell DW, Douville C, Byrd S, Schoonover K: Dynamic transcranial Doppler assessment of positional vertebrobasilar ischemia. Stroke 25:1776-1783, 1994

45. Sugiu K, Agari T, Tokunaga K, Nishida A, Date I: Endovascular treatment for bow hunter's syndrome: case report. Minim Invasive Neurosurg 52:193-195, 2009

46. Toole JF, Tucker SH: Influence of head position upon cerebral circulation. Studies on blood flow in cadavers. Arch Neurol 2:616-623, 1960

47. Tsutsumi S, Ito M, Yasumoto Y: Simultaneous bilateral vertebral artery occlusion in the lower cervical spine manifesting as bow hunter's syndrome. Neurol Med Chir (Tokyo) 48:90-94, 2008

48. Ujifuku K, Hayashi K, Tsunoda K, Kitagawa N, Hayashi T, Suyama K, et al: Positional vertebral artery compression and vertebrobasilar insufficiency due to a herniated cervical disc. J Neurosurg Spine 11:326-329, 2009

49. Vates GE, Wang KC, Bonovich D, Dowd CF, Lawton MT: Bow hunter stroke caused by cervical disc herniation. Case report. J Neurosurg 96 (1 Suppl):90-93, 2002
50. Velat GJ, Reavey-Cantwell JF, Ulm AJ, Lewis SB: Intraoperative dynamic angiography to detect resolution of Bow Hunter's syndrome: technical case report. Surg Neurol 66:420-423, 2006

51. Vilela MD, Goodkin R, Lundin DA, Newell DW: Rotational vertebrobasilar ischemia: hemodynamic assessment and surgical treatment. Neurosurgery 56:36-45, 2005

52. Wakayama K, Murakami M, Suzuki M, Ono S, Shimizu N: Ischemic symptoms induced by occlusion of the unilateral vertebral artery with head rotation together with contralateral vertebral artery dissection-case report. J Neurol Sci 236:87-90, 2005

53. Whitmore RG, Simon SL, Hurst RW, Nisenbaum HL, Kasner SE, Zager EL: Bow hunter's syndrome caused by accessory cervical ossification: posterolateral decompression and the use of intraoperative Doppler ultrasonography. Surg Neurol 67:169-171, 2007

54. Yang PJ, Latack JT, Gabrielsen TO, Knake JE, Gebarski SS, Chandler WF: Rotational vertebral artery occlusion at C1C2. AJNR Am J Neuroradiol 6:96-100, 1985

\section{Author Contributions}

Conception and design: both authors. Acquisition of data: both authors. Analysis and interpretation of data: both authors. Drafting the article: both authors. Critically revising the article: both authors. Reviewed submitted version of manuscript: both authors. Approved the final version of the manuscript on behalf of both authors: Dailey.

\section{Correspondence}

Andrew T. Dailey, Department of Neurosurgery, University of Utah, 175 N. Medical Dr. E, Salt Lake City, UT 84132. email: neuropub@hsc.utah.edu. 